\title{
Solute diffusion into cell walls in solution-impregnated wood under conditioning process IV: effect of temperature on solute diffusivity
}

\author{
Soichi Tanaka ${ }^{1} \cdot$ Masako Seki $^{2} \cdot$ Tsunehisa Miki $^{2} \cdot$ Kenji Umemura $^{1} \cdot$ \\ Kozo Kanayama ${ }^{1}$
}

Received: 14 January 2017 / Accepted: 19 July 2017/Published online: 4 August 2017

(C) The Japan Wood Research Society 2017

\begin{abstract}
This study has focused on solute diffusing into cell walls in solution-impregnated wood under conditioning, process of evaporating solvent. The amount of the diffusion is known to be determined by the solute diffusivity and the solute-concentration difference between cell walls and cell cavities. Purpose of this paper was to clarify the effect of temperature only on the solute diffusivity that is directionally related to the thermal vibration of the solute molecule. The cross-cut block of hinoki (Chamaecyparis obtusa), polyethylene glycol (PEG1540), and water was employed as wood sample, solute, and solvent, respectively. The sample impregnated with a 20 mass $\%$ solution was conditioned at 20 , 35 , or $50{ }^{\circ} \mathrm{C}$ to finish the solute diffusion evaluated using the dimension of the sample that was conditioned followed by drying in a vacuum. To unify the solute-concentration difference, for all temperatures, the equilibrium moisture content was unified and the solvent-evaporation rate was controlled in three ways during conditioning. The solute diffusivity was higher in order of 35,50 , and $20^{\circ} \mathrm{C}$, which was evaluated by the solute diffusion at the same evaporation rate. It is clarified that the diffusivity increases with increasing the dimension of cell walls rather than with increasing the thermal vibration of solute molecule.
\end{abstract}

Keywords Impregnated wood $\cdot$ Conditioning · Temperature $\cdot$ Solute diffusivity $\cdot$ Moisture variation

Soichi Tanaka

soichi_tanaka@rish.kyoto-u.ac.jp

1 Research Institute for Sustainable Humanosphere, Kyoto University, Uji, Kyoto 611-0011, Japan

2 Structural Materials Research Institute, National Institute of Advanced Industrial Science and Technology, Nagoya, Aichi 463-8560, Japan

\section{Introduction}

Chemical treatment of wood is one of the major methods to change its properties such as biodegradability, combustibility, and dimensional instability [1]. In the treatments, the chemical substance has been developed and introduced into wood to control these properties that can lead to some troubles during usage of wood [2], for example, the deformation of wood under changing climate is decreased by the bulking effect of the introduced substance such as polyethylene glycol (PEG) or phenolformaldehyde resin. For the effective improvement especially of the dimensional stability, the chemical substance is required to exist in wood cell walls rather than in cell cavities [3].

In the general treatment process, wood is impregnated with a solution of the chemical substance and is subsequently conditioned in the atmosphere to evaporate the solvent from the impregnated wood. Our previous study has shown that most of chemical substance, or solute, diffuses into cell walls during the conditioning process rather than during the impregnation process [4].

The solute diffusion into cell walls was suggested to be driven by the higher solute concentration in cell cavities than that in cell walls, which is caused by the higher evaporation rate of solvent from cell cavities than that from cell walls [5]. The amount of solute diffusing into cell walls is considered to be increased by increasing the following two factors. The first factor is the difference in solute concentration between cell cavities and cell walls. The second factor is the solute diffusivity into cell walls [6]. It should be noticed that both these factors may be affected by the atmospheric state such as relative humidity (RH) and temperature during the conditioning. The goal of our work was to determine the atmospheric states that 
maximize the amount of the solute diffused into cell walls by controlling the solute diffusion during conditioning process.

In the previous studies [6-8], we have examined the effect of $\mathrm{RH}$ with a constant temperature on the solute diffusion into cell walls during the conditioning. In these studies, cross-cut wood samples were used, since they are favorable for causing the solute-concentration difference between cell walls and cell cavities. As solute and solvent in these studies, PEGs and water, respectively, were employed, because the amount of water or PEGs in cell walls and cell cavities can be related to mass or dimension, respectively, of the impregnated wood [9-21]. Most of PEGs are confirmed to diffuse into cell walls during conditioning [4], though the cell walls impregnated with aqueous-PEG solution absorbs far smaller amount of PEGs [22]. Figure 1 shows the mechanism of the effect of the RH on the solute diffusion. It has been clarified that the $\mathrm{RH}$ affects the moisture variation in the impregnated wood [6]. The moisture variation also has been clarified to affect the solute-concentration difference [6] and the solute diffusivity [7], both of which determine the amount of the solute diffused into cell walls (Fig. 1). On the other hand, the mechanism of the effect of temperature on the solute diffusion has not been investigated. Though there exist studies on the effect of temperature on the amount of the diffused solute [22, 23], the RH was not be controlled at all, which made it difficult to understand the effect of temperature.

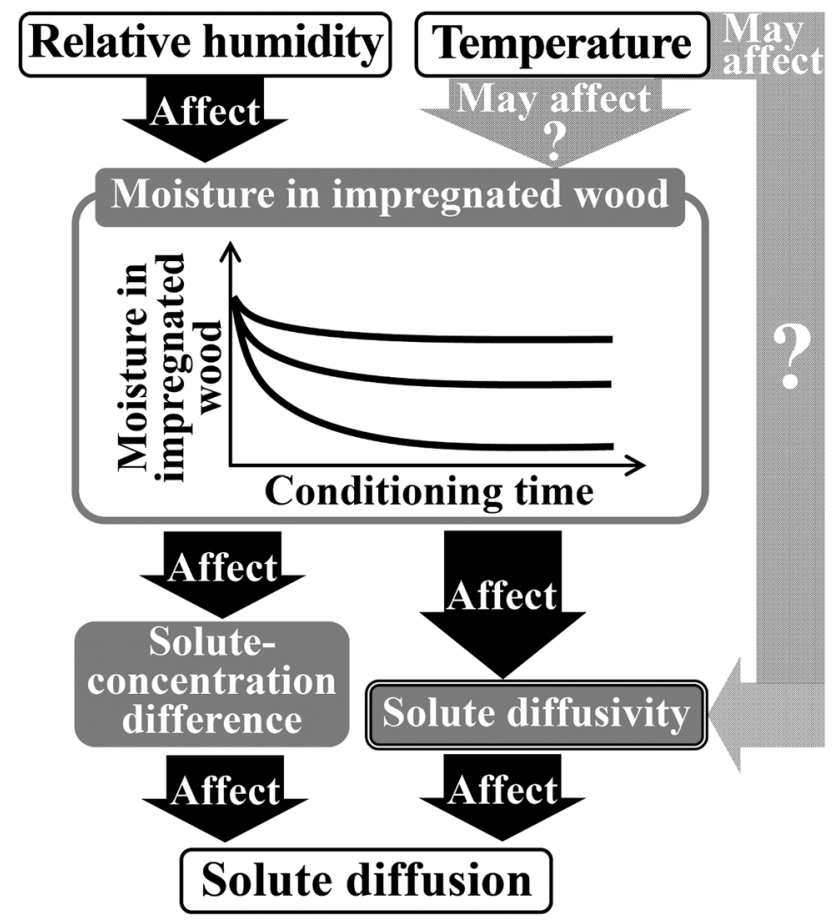

Fig. 1 Effect on solute diffusion of relative humidity (RH) clarified in our previous studies and of temperature to be examined in this paper
The objective of our study was to clarify the effect of temperature on the solute diffusion into cell walls. In the diffusion, it is more important to focus on the solute diffusivity (Fig. 1) than the solute-concentration difference. This was because the diffusivity may include the factor of the thermal vibration of the solute molecule that may be controlled only by the temperature. It is, therefore, important to evaluate the effect of temperature only on the diffusivity. The temperature, however, may also affect the concentration difference (Fig. 1). We noticed that the concentration difference would be unified if the moisture variation during the conditioning was unified for all the controlled temperatures (Fig. 1).

The purpose of this paper was to clarify the effect of the temperature on the solute diffusivity. Cross-cut wood samples were impregnated with a solution including PEGs and water as solute and solvent, respectively. These samples were conditioned in three ways of the temperature until the end of the solute diffusion. To unify the moisture variation or the solute-concentration difference (Fig. 1), for all ways, the conditioning was controlled according to the following atmospheric state.

1. For all temperatures, RHs were chosen to unify an equilibrium moisture content (MC), at which the impregnated samples swelled maximally with a temperature of $35^{\circ} \mathrm{C}$, confirmed in our previous study [6].

2. For each temperature, the evaporation rate during conditioning was controlled in three ways, because it was difficult to unify the evaporation rate for all temperatures.

We examined the effect of temperature on the relation between the evaporation rate and the amount of the diffused solute that was evaluated using the dimension of the samples. The solute diffusivity was discussed based on the amount of the diffused solute at the same evaporation rate.

\section{Materials and methods}

\section{Sample preparation and impregnation process}

Nine cross-cut samples, with dimensions of $5 \mathrm{~mm} \times 25 \mathrm{~mm} \times 25 \mathrm{~mm}$ in longitudinal $(L)$, radial $(R)$, tangential $(T)$ directions, respectively, were subsequently prepared from a block of hinoki (Chamaecyparis obtusa). The samples were impregnated with deionized water and left in it for 2 months, and their area in RT-cross section, $s_{\mathrm{A}}$, was measured. They were conditioned at $20{ }^{\circ} \mathrm{C}$ with $\mathrm{RH}$ of $60 \%$ for 11 months, and subsequently dried at $105{ }^{\circ} \mathrm{C}$ to relatively constant mass, $m_{\mathrm{O}}$, their RT-crosssectional area, $s_{\mathrm{O}}$, and volume. Their average oven-dry density was $0.380 \pm 0.001 \mathrm{~g} / \mathrm{cm}^{3}$. The dried samples were 
impregnated with an aqueous solution of polyethylene glycol (PEG1540, E.P., Wako) with concentration of 20 mass \%, and left at $20{ }^{\circ} \mathrm{C}$ in the solution for 7 months.

\section{Conditioning process}

As the conditioning temperatures, 20,35 , or $50{ }^{\circ} \mathrm{C}$ was chosen for the following two reasons. The first reason was that the impregnated wood in practice is often conditioned at temperatures higher than the room temperature. The second reason was that the PEG1540, employed as a solute, may possibly be decomposed with high temperature; for example, the PEG1540 is confirmed to slightly decompose during the heat treatment at $80{ }^{\circ} \mathrm{C}$ for 1 week [23]. For 20,35 , or $50{ }^{\circ} \mathrm{C}$, saturated aqueous solution of potassium iodide (KI), sodium nitrate $\left(\mathrm{NaNO}_{3}\right)$, or sodium chloride $(\mathrm{NaCl})$ was placed in the container on the bottom (Fig. 2) to control the RH in it to 70,72 , or $74 \%$, respectively [24]. These RHs were determined to unify the equilibrium $\mathrm{MC}$ for all the temperatures on the basis of preliminary experiment. In the container, another container with a hole on the bottom was placed over the saturated solution (Fig. 2). The diameter of the hole, $d$, was determined to be 10.0, 17.6 , or $34.0 \mathrm{~mm}$ for $20^{\circ} \mathrm{C}, 4.1,7.0$, or $14.1 \mathrm{~mm}$ for $35^{\circ} \mathrm{C}$, and $2.5,4.5$, or $7.5 \mathrm{~mm}$ for $50^{\circ} \mathrm{C}$. These diameters were determined according to the preliminary experiment, to control the rate of the water evaporation from the sample in the similar range for all temperatures. The conditioning state is summarized in Table 1.

Each impregnated wood sample was conditioned over the hole of the inner container (Fig. 2) according to each conditioning state (Table 1) for $2.03 \times 10^{3} \mathrm{~h}$. All the samples were subsequently dried at $20{ }^{\circ} \mathrm{C}$ over a phosphorous pentoxide $\left(\mathrm{P}_{2} \mathrm{O}_{5}\right)$ in a vacuum to reach to the relatively constant RT-cross-sectional area.

The mass and RT-cross-sectional area of the sample during the conditioning, $m(t)$ and $s(t)$, respectively, were measured at conditioning time, $t$, of $0,1.6,4.9,11,23,46,95$, $178,263,418,724,1177$, and $2027 \mathrm{~h}$ indicated by $t_{i}(i=1$, $2, \ldots, 13$, respectively). The mass and the area after reaching their constant value during drying in a vacuum, $m_{\mathrm{V}}$ and $s_{\mathrm{V}}$, respectively, were measured three times. The MC, $M(t)$, and relative swelling, $r(t)$, of the impregnated samples under conditioning were calculated using the following equations:

$M(t)=\frac{100\left\{m(t)-m_{\mathrm{V}}\right\}}{m_{\mathrm{V}}}(\%)$,

$r(t)=\frac{s(t)-s_{\mathrm{O}}}{s_{\mathrm{A}}-s_{\mathrm{O}}}$.

Weight percent gain (WPG) after drying in a vacuum was calculate using the following equation:

$W_{\mathrm{V}}=\frac{100\left(m_{\mathrm{V}}-m_{\mathrm{O}}\right)}{m_{\mathrm{O}}}(\%)$.

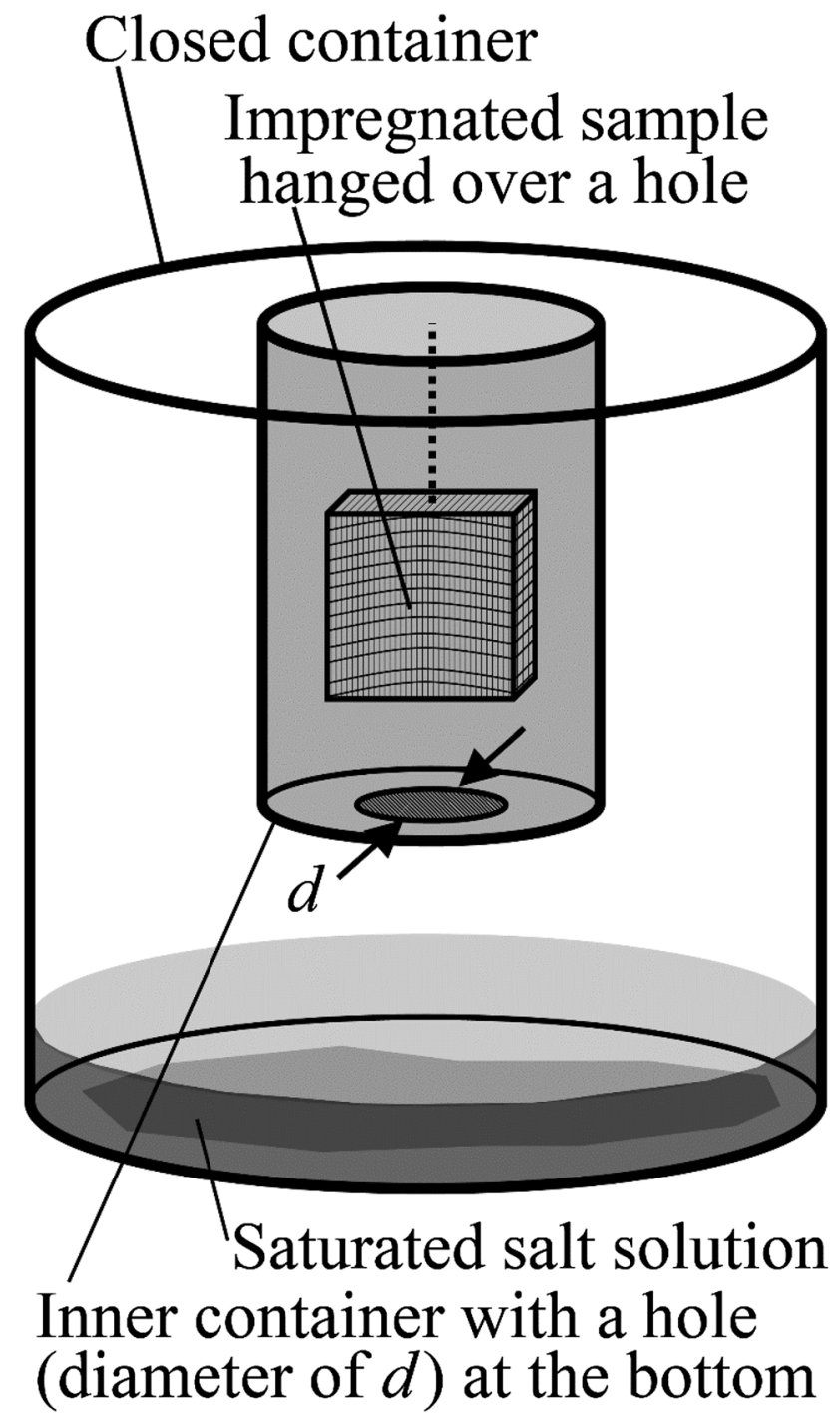

Fig. 2 Containers for conditioning of impregnated sample

The values of $W_{\mathrm{V}}$, are also summarized in Table 1 , were not so different among all the conditions. This confirms that the total amount of PEGs in each sample after the conditioning is not so different among all temperatures.

The relative swelling after drying in a vacuum, $r_{\mathrm{v}}$, was calculated using the following equation:

$r_{\mathrm{V}}=\frac{s_{\mathrm{V}}-s_{\mathrm{O}}}{s_{\mathrm{A}}-s_{\mathrm{O}}}$.

\section{Results and discussion}

\section{Moisture variation during conditioning}

The temporal variability of $\mathrm{MC}$ during conditioning is shown as plots in Fig. $3 \mathrm{a}$, b, or $\mathrm{c}$ for 20,35 , or $50{ }^{\circ} \mathrm{C}$. The 
Table 1 Conditioning state and WPG (weight percent gain) after all process

\begin{tabular}{|c|c|c|c|c|}
\hline Temperature $\left({ }^{\circ} \mathrm{C}\right)$ & $\begin{array}{l}\text { Relative humidity } \\
\text { (RH) }(\%)\end{array}$ & $\begin{array}{l}\text { Kind of salt employed in } \\
\text { saturated solution }\end{array}$ & $\begin{array}{l}\text { Diameter of a hole } \\
\text { (Fig. 2) } d(\mathrm{~mm})\end{array}$ & $\begin{array}{l}\text { WPG after all } \\
\text { processes } W_{\mathrm{V}}(\%)^{\mathrm{a}}\end{array}$ \\
\hline \multirow[t]{3}{*}{20} & \multirow[t]{3}{*}{70} & \multirow[t]{3}{*}{ Potassium iodide (KI) } & 10.0 & $39.4^{\mathrm{b}} \pm 0.3^{\mathrm{c}}$ \\
\hline & & & 17.6 & $39.6 \pm 0.2$ \\
\hline & & & 34.0 & $39.6 \pm 0.2$ \\
\hline \multirow[t]{3}{*}{35} & \multirow[t]{3}{*}{72} & \multirow[t]{3}{*}{ Sodium nitrate $\left(\mathrm{NaNO}_{3}\right)$} & 4.1 & $39.2 \pm 0.1$ \\
\hline & & & 7.0 & $39.4 \pm 0.2$ \\
\hline & & & 14.1 & $39.7 \pm 0.2$ \\
\hline \multirow[t]{3}{*}{50} & \multirow[t]{3}{*}{74} & \multirow[t]{3}{*}{ Sodium chloride $(\mathrm{NaCl})$} & 2.5 & $39.3 \pm 0.1$ \\
\hline & & & 4.5 & $38.9 \pm 0.2$ \\
\hline & & & 7.5 & $39.4 \pm 0.2$ \\
\hline
\end{tabular}

${ }^{a}$ Measured three times

b Average value

c Standard deviation, affected by the moisture absorbed on the sample until the measurement just after drying in a vacuum over $\mathrm{P}_{2} \mathrm{O}_{5}$

moisture variation, $M$, changed by changing of the diameter, $d$, for all temperatures. The initial and equilibrium MCs, $M_{\mathrm{I}}$ and $M_{\mathrm{E}}$, are summarized in Table 2 . The values of $M_{\mathrm{I}}$ and $M_{\mathrm{E}}$ were not so different among all conditioning states. This confirms that the equilibrium MCs were unified for all the conditioning states.

To estimate water-evaporation-rate constant, $k$, the following equation was assumed as the moisture variation, $M(t)$ :

$M(t)=M_{\mathrm{E}}+\left(M_{\mathrm{I}}-M_{\mathrm{E}}\right) \exp (-k t)$.

The value of $k$ was estimated using $M_{\mathrm{I}}$ and $M_{\mathrm{E}}$ values in Table 2, so that the following residual sum of squares, $J$, became the minimum value (the least square method):

$J=\sum_{i=1}^{13}\left\{M_{i}-M\left(t_{i}\right)\right\}^{2}$,

where $M_{i}$ and $t_{i}(i=1,2, \cdots, 13)$ were the measured MC and the corresponding time, respectively (Fig. 3a-c).

The estimated moisture variations were shown as lines in Fig. $3 \mathrm{a}-\mathrm{c}$, and the estimated values of $k$ and $J$ are also summarized in Table 2. The lines were well fitted to the experimental plots, and the value of $J$ was not so different among all the conditioning states. This indicates that Eq. (5) can explain the moisture variation during conditioning. Figure 4 shows the relation of evaporationrate constant, $k$, to the diameter of the hole, $d$. For all temperatures, the values of $k$ were correlated strongly with the values of $d\left(R^{2}=0.988,0.996\right.$, and 0.993 for regression lines of 20,35 , and $50{ }^{\circ} \mathrm{C}$, respectively). The slope of the regression line increased with temperature. These findings indicate that the evaporation-rate constant was successfully controlled by the diameter of a hole (Fig. 2).

\section{Dimensional change during conditioning}

Figure 5 shows the temporal variability of relative swelling of the impregnated samples during conditioning for each temperature. The sample constantly swelled for 35 and $50{ }^{\circ} \mathrm{C}$, while it swelled followed by shrinking for $20^{\circ} \mathrm{C}$. This phenomenon can be explained by the following mechanism.

1. Mixture ratio of solute to solvent (water) increases during conditioning, since the MC decreases (Fig. 3).

2. Relation of relative swelling to this ratio (Fig. 6) shows an upward convex curve with a maximum value of relative swelling [15]. This relation can be explained by the decreasing and subsequent increasing in the cohesive forces among all the solute (PEG)- and solvent (water)-molecules in wood with increasing the mixture ratio [9, 15]. The impregnated sample is known to swell, or the substances adsorbed in the cell walls increased if the cohesive force is decreased [25].

3. The temperature is expected to affect the mixture ratio at which the cohesive force is minimum, or the $\mathrm{MC}$ at which the sample swells maximally (Fig. 6).

4. The mixture ratio at the end of conditioning is considered to be smaller and larger than the ratio causing the maximum swelling for 35 or $50{ }^{\circ} \mathrm{C}$ and for $20{ }^{\circ} \mathrm{C}$, respectively (Fig. 6).

In our previous studies [6, 7], the solution-impregnated wood under conditioning swells with decreasing RH down to a level, and subsequently shrinks with decreasing $\mathrm{RH}$ to the further lower level, respectively, which is consistent with this mechanism.

The relative swelling became constant until the end of the conditioning (Fig. 5). The relative swelling during 

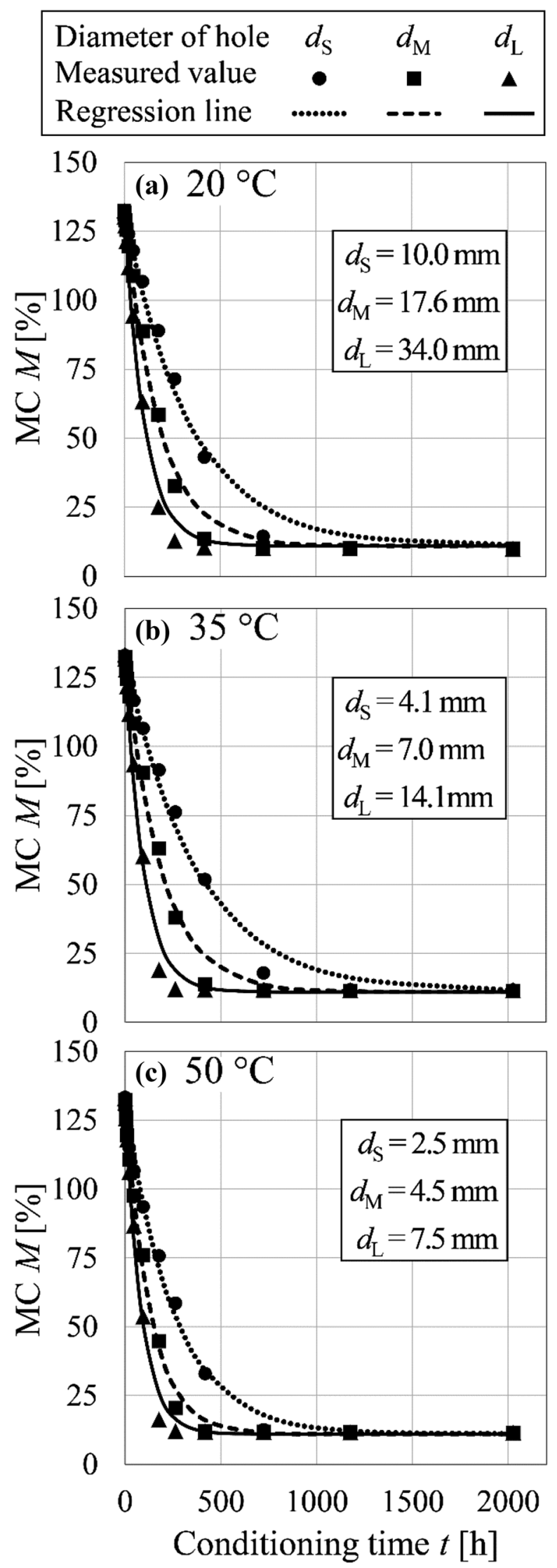

4Fig. 3 Temporal variability of moisture content (MC) controlled using diameter of a hole, $d$ (Fig. 2), for each temperature

conditioning is known to increase with the total amount of substance in cell walls [9-21] and thus to imply the migration of substance into and out of cell walls. These findings indicate that the solute diffusion almost finished until the end of the conditioning.

\section{Dependence of solute diffusion on temperature}

Figure 7 shows the effect of temperature on the relation between the evaporation-rate constant and the relative swelling after all processes, which is known to be proportional to the amount of the diffused solute into cell walls during conditioning $[7,26]$.

The amount of the diffused solute increased with increasing the evaporation-rate constant (Fig. 7). This trend agreed with the trend when the impregnated wood swells during conditioning in our previous study [8]. The cause of this trend is discussed later.

The amount of the diffused solute was larger in order of 35,50 , and $20^{\circ} \mathrm{C}$ when compared at the same evaporationrate constant (Fig. 7). This trend coincides with the temperature dependence only on the solute diffusivity, since the moisture variation, or the solute-concentration difference (Fig. 1), was almost unified for all the temperatures. The higher solute diffusivity in order of 35,50 , and $20^{\circ} \mathrm{C}$, however, could not be explained only by the following facts; the thermal vibration of the solute molecule is more active for higher temperature; and the freezing point of PEG1540 (Safety data sheet of Wako Pure Chemical Industries, Ltd., Osaka, Japan), employed as a solute, is $40-50{ }^{\circ} \mathrm{C}$. The reason for this is discussed later.

\section{Factors affecting solute diffusivity}

Figure 8 shows the relation between the relative swelling at the end of conditioning and that after drying in a vacuum. Since the amount of the diffused solute is in proportion to the relative swelling after drying in a vacuum [7, 26], the relation in Fig. 8 indicates that the solute diffusion increased with the relative swelling at the end of conditioning. This relation can be explained using the following mechanism: the solute maintained its diffusivity to some extent at the equilibrium MC, about $11 \%$ (Table 2); the capacity of the space into which the solute can diffuse during conditioning increases with increasing the dimension of the sample, or with swelling of cell walls.

This mechanism can explain the reason for the increase in solute diffusion with increasing evaporation-rate 
Table 2 Initial and equilibrium moisture contents (MCs), evaporation-rate constant, and residual sum of squares for each conditioning state

\begin{tabular}{llllll}
\hline $\begin{array}{l}\text { Temperature } \\
\left({ }^{\circ} \mathrm{C}\right)\end{array}$ & $\begin{array}{l}\text { Diameter } \\
d(\mathrm{~mm})\end{array}$ & $\begin{array}{l}\text { Initial } \mathrm{MC} M_{\mathrm{I}} \\
(\%)\end{array}$ & $\begin{array}{l}\text { Equilibrium MC } \\
M_{\mathrm{E}}(\%)\end{array}$ & $\begin{array}{l}\text { Evaporation-rate constant } \\
k\left(\times 10^{-2} \mathrm{~h}^{-1}\right)\end{array}$ & $\begin{array}{l}\text { Minimum residual sum of squares } \\
J\left(\times 10^{2} \%^{2}\right)\end{array}$ \\
\hline 20 & 10.0 & 131.7 & 10.0 & 0.30 & 2.3 \\
& 17.6 & 132.4 & 10.0 & 0.56 & 2.0 \\
35 & 34.0 & 132.4 & 9.9 & 0.97 & 1.9 \\
& 4.1 & 133.0 & 11.7 & 0.27 & 2.0 \\
& 7.0 & 132.4 & 11.3 & 0.53 & 2.7 \\
50 & 14.1 & 133.2 & 11.5 & 1.04 & 2.1 \\
& 2.5 & 133.3 & 11.6 & 0.4 & 1.3 \\
& 4.5 & 132.4 & 11.6 & 0.8 & 1.6 \\
& 7.5 & 133.1 & 11.6 & 1.2 & \\
\hline
\end{tabular}

a Average value

b Standard deviation

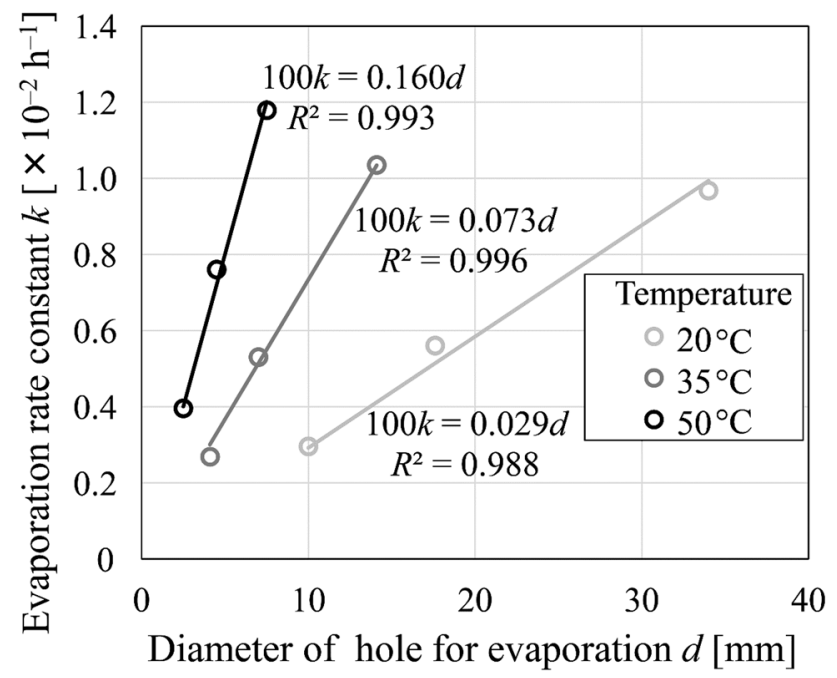

Fig. 4 Relation of water-evaporation-rate constant to diameter of a hole (Fig. 2) for each temperature

constant for 35 and $50{ }^{\circ} \mathrm{C}$ (Fig. 7). This increase is caused by the increase in the capacity of the space with increasing the rate. On the other hand, the relation between the solute diffusion and the evaporation-rate constant for $20^{\circ} \mathrm{C}$ cannot be explained by the mechanism. Though this was assumed to be related to the shrinking of the sample (Fig. 5) during conditioning, the reason for this was not clear, which is the challenge to be solved.

This mechanism can also explain the reason for the higher solute diffusivity at $35{ }^{\circ} \mathrm{C}$ than $50{ }^{\circ} \mathrm{C}$ (Fig. 7). When considering the effect of temperature, however, thermal vibration is one of the most important factor that also affects the diffusivity, as described above. The diffusivity is considered to increase with increasing the thermal vibration. This consideration indicates that the effect on the

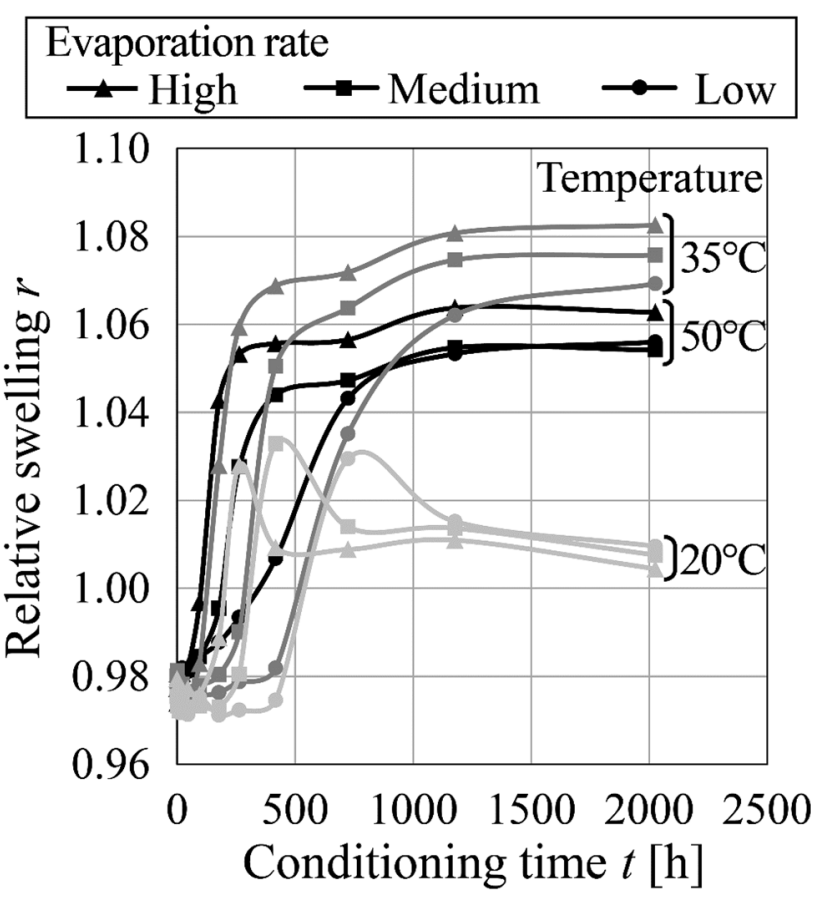

Fig. 5 Temporal variability of relative swelling in three ways of evaporation-rate constant for each temperature

solute diffusivity of the thermal vibration is smaller than that of the cell-wall swelling during conditioning.

There remains the possibility such that the swelling of the sample during conditioning would become larger (Fig. 6) if the other RHs and temperatures were selected. It is therefore important to clarify the combination of temperature and $\mathrm{RH}$ where the impregnated sample swells maximally during conditioning.

The solute diffusivity in this study was evaluated only when the solute diffusion finished during conditioning 


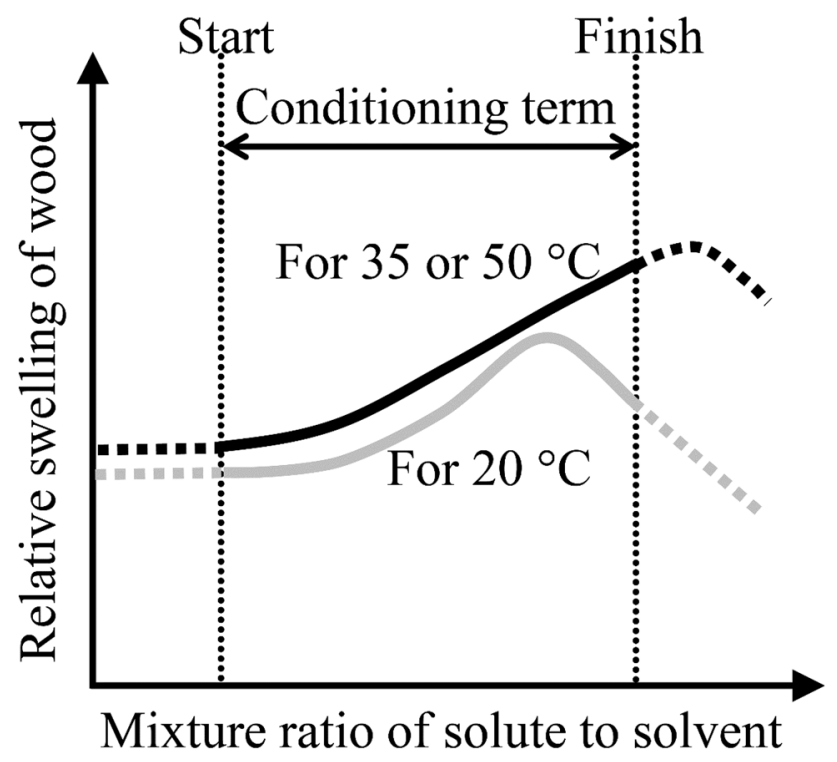

Fig. 6 Approximate relation of relative swelling to mixture ratio of solute (PEG) and solvent (water) [15] considered for each temperature

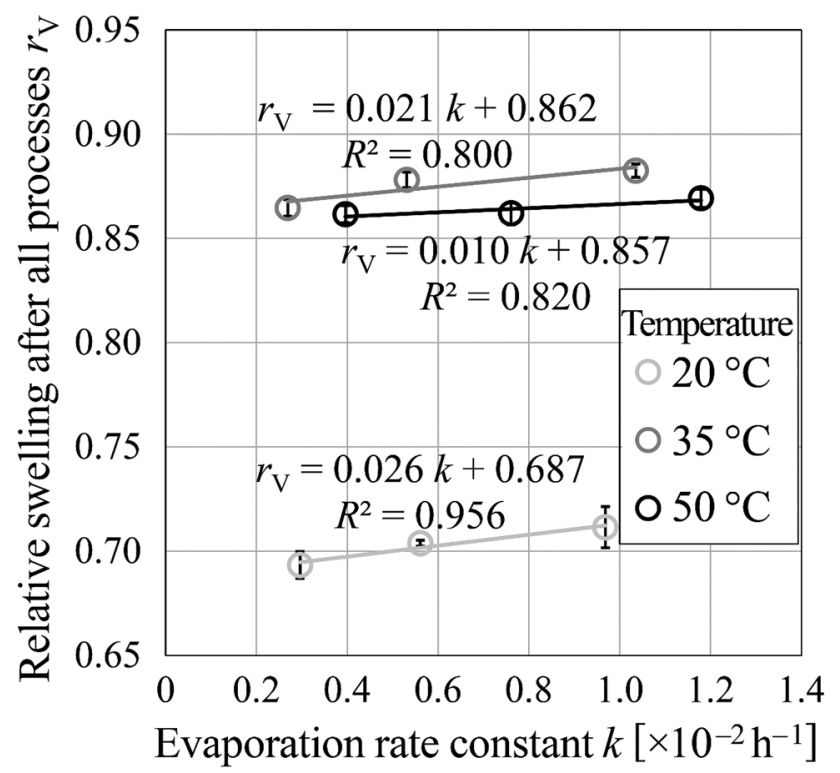

Fig. 7 Relation of relative swelling after all processes to evaporation-rate constant for each temperature. Error bars standard deviation

(Fig. 5). The time until the solute diffusion finished was expected to decrease with increasing temperature, since the thermal vibration is more active at higher temperature. This was supported by the fact that increasing rate of the swelling at early stage of conditioning increased with temperature when compared in the same evaporation-rateconstant group (Fig. 5). These indicate that the effect of temperature on the solute-diffusion rate should be clarified by evaluating the time to finish the solute diffusion for each temperature, as the next challenge.

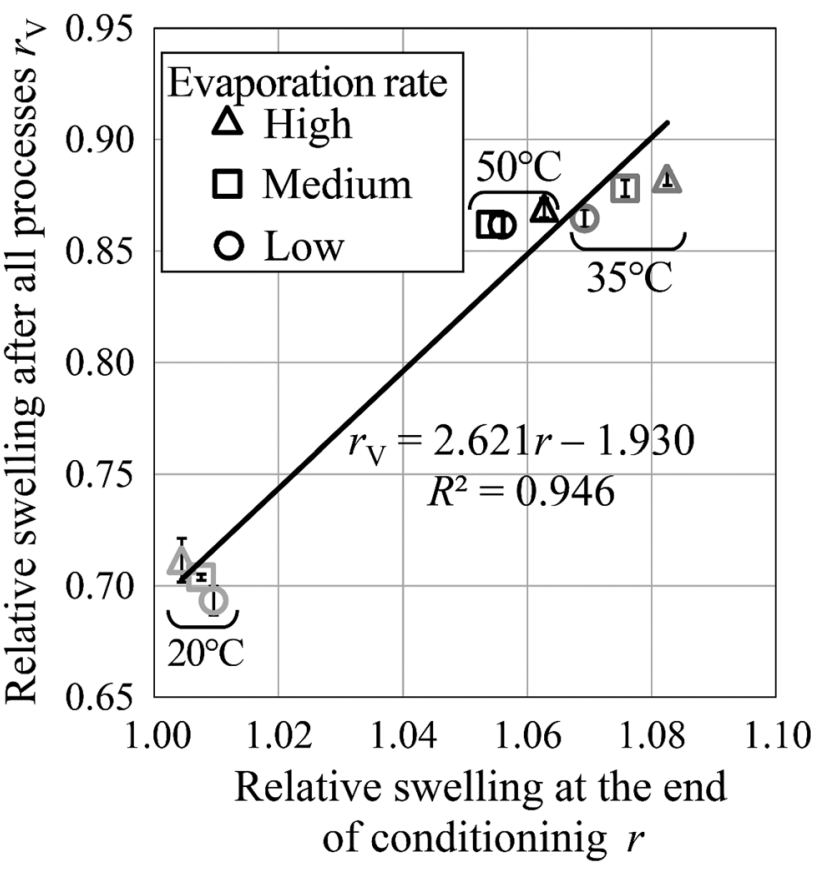

Fig. 8 Relation between relative swelling at the end of conditioning and that after all processes in three ways of evaporation-rate constant for each temperature. Error bars standard deviation

\section{Conclusion}

This paper dealt with the effect of temperature on the solute diffusivity into cell walls during conditioning of solution-impregnated wood. The cross-cut block of hinoki, PEG1540, and water was employed as wood sample, solute, and solvent, respectively. The wood sample impregnated with a 20 mass \% solution was conditioned at 20,35 , or $50{ }^{\circ} \mathrm{C}$ until the dimension of the sample became almost constant. The amount of diffused solute during conditioning was evaluated using the dimension of the sample that was conditioned followed by drying in a vacuum. To unify the solute-concentration difference, for all temperatures, the equilibrium MC was unified and the evaporation-rate constant was controlled in three ways during conditioning. The solute diffusivity was evaluated using the amount of the diffused solute at the same evaporation-rate constant. The diffusivity was higher in order of 35 , 50, and $20^{\circ} \mathrm{C}$. It is clarified that the diffusivity increases with increasing the dimension of cell walls rather than with increasing the thermal vibration of solute molecule.

To finish conditioning in shorter time, however, it is clearly preferable to condition at as high temperature as possible. The following subject, therefore, should be studied as the next challenge for the conditioning process:

1. to clarify the combination of $\mathrm{RH}$ and temperature where impregnated wood swells maximally; 
2. to clarify the effect of temperature on the solutediffusion rate.

\section{References}

1. Inoue M, Ogata S, Nishikawa M, Otsuka Y, Kawai S, Norimoto M (1993) Dimensional stability, mechanical properties, and color changes of low molecular weight melamine-formaldehyde resin impregnated wood (in Japanese). Mokuzai Gakkaishi 39:181-189

2. Norimoto M, Grill J (1993) Structure and properties of chemically treated wood. In: Recent research on wood and wood-based materials. In: Shiraishi N, Kajita H, Norimoto M (eds) Current Japanese materials research, vol 11. Elsevier Applied Science, London, pp 135-154

3. Furuno T, Goto T (1978) Structure of the interface between wood and synthetic polymer. XI. The role of polymer in the cell wall on the dimensional stability of wood polymer composite (WPC). Mokuzai Gakkaishi 24:287-293

4. Tanaka S, Seki M, Miki T, Shigematsu I, Kanayama K (2016) Solute diffusion into cell walls in solution-impregnated wood under conditioning process II: effect of solution concentration on solute diffusion. J Wood Sci 62:146-155

5. Stamm AJ (1956) Dimensional stabilization of wood with carbonwaxes. Forest Prod J 6:201-204

6. Tanaka S, Miki T, Seki M, Shigematsu I, Kanayama K (2015) Mechanism verification of solute diffusion into cell walls in solution impregnated wood under conditioning process: effect of relative humidity on swelling and shrinkage behavior of wood impregnated with an aqueous solution of polyethylene glycol (in Japanese). J Soc Mater Sci Japan 64:369-374

7. Tanaka S, Seki M, Miki T, Shigematsu I, Kanayama K (2015) Solute diffusion into cell walls in solution-impregnated wood under conditioning process I: effect of relative humidity on solute diffusivity. J Wood Sci 61:543-551

8. Tanaka S, Seki M, Miki T, Shigematsu I, Umemura K, Kanayama K (2016) Effect of solvent evaporation rate on solute diffusion into cell walls in solution-impregnated wood under conditioning process (in Japanese). J Soc Mater Sci Japan 65:359-364

9. Stamm AJ (1964) Dimensional stabilization. Wood and cellulose science. Ronald Press, New York, pp 312-342

10. Ishimaru Y (1993) PEG to mokuzai no hanashi (in Japanese). Mokuzaihozon 19:204-218

11. Jeremic D, Cooper P, Heyd D (2007) PEG bulking of wood cell walls as affected by moisture content and nature of solvent. Wood Sci Technol 41:597-606

12. Jeremic D, Cooper P (2009) PEG quantification and examination of molecular weight distribution in wood cell walls. Wood Sci Technol 43:317-329
13. Jeremic D, Quijano-Solis C, Cooper P (2009) Diffusion rate of polyethylene glycol into cell walls of red pine following vacuum impregnation. Cellulose 16:339-348

14. Kitani Y, Ohsawa J, Nakato K (1970) Adsorption of polyethylene glycol on water-swollen wood versus molecular weight (in Japanese). Mokuzai Gakkaishi 16:326-333

15. Sadoh T, Hashihira M (1973) A note on the swelling of wood with polyethylene glycols (in Japanese). Bull Kyoto Univ For 45:227-237

16. Schneider VA (1969) Contribution on the dimensional stabilization of wood with polyethylene glycol-Part 1: basic Investigation on the dimensional stabilization of wood with polyethylene glycol (in German). Holz Roh Werkst 27:209-224

17. Schneider VA (1970) Contribution on the dimensional stabilization of wood with polyethylene glycol-Part 2: investigation of changes of wood properties by PEG impregnation and on the effectiveness of various impregnation processes (in German). Holz Roh Werkst 28:20-34

18. Stamm AJ (1959) The dimensional stability of wood. Forest Prod J 9:375-381

19. Stamm AJ (1964) Factors affecting the bulking and dimensional stabilization of wood with polyethylene glycols. Forest Prod J 14:403-408

20. Tarkow H, Feist WC, Southerland CF (1966) Interaction of wood with polymeric materials penetration versus molecular size. For Prod J 16:61-65

21. Sadoh T (1967) The dimensional changes of wood during polyethylene glycol treatment and some elastic properties of the treated wood. Mokuzai Gakkaishi 13:41-45

22. Yamaguchi T, Ishimaru Y, Urakami H (1999) Effect of temperature on dimensional stability of wood with polyethylene glycol II. Temperature dependence of PEG adsorption and mechanical properties of treated wood (in Japanese). Mokuzai Gakkaishi 45:441-447

23. Yamaguchi T, Ishimaru Y, Urakami H (1999) Effect of temperature on dimensional stability of wood with polyethylene glycol I. Bulking effect (in Japanese). Mokuzai Gakkaishi 45:434-440

24. Greenspan L (1977) Humidity fixed points of binary saturated aqueous solutions. J Res Natl Bur Stand Sect A Phys Chem 81A:89-96

25. Ishimaru Y, Sakai H (1988) Swelling of wood in liquid mixtures I. water-ethanol and water-acetone (in Japanese). Mokuzai Gakkaishi 34:889-895

26. Tanaka S, Seki M, Miki T, Shigematsu I, Umemura K, Kanayama K (2017) Solute diffusion into cell walls in solution-impregnated wood under conditioning process III: effect of relative-humidity schedule on solute diffusion into shrinking cell walls. J Wood Sci 63:263-270 